\title{
Effect of progesterone, administered via intravaginal rings, on serum concentrations of oestradiol, FSH, LH and prolactin in women
}

\author{
T. Bäckström*, K. Carlström† , B. von Schoultz $\ddagger$ and J. Toivonen § \\ * Department of Physiology, University of Umeå, Umeå, Sweden; $\dagger$ Hormone Laboratory, \\ Department of Obstetrics and Gynaecology, Sabbatsbergs Hospital, Stockholm, Sweden; \\ $\ddagger$ Department of Obstetrics and Gynaecology, University of Umeä, Sweden; and \\ $\S$ Steroid Hormone Research Laboratory, Department of Medical Chemistry, University of \\ Helsinki, Helsinki, Finland
}

\begin{abstract}
Summary. Intravaginal rings containing progesterone were inserted on Day 5 of the cycle to 8 healthy, normally menstruating women. Blood samples were taken during Days 4-22 of the cycle at 2-3-day intervals.

The plasma progesterone levels obtained after the insertion were between 7.5 and $21 \mathrm{nmol} / \mathrm{l}$. Four subjects showed no increase in plasma oestradiol concentrations. The subjects showing increased plasma oestradiol levels also showed a positive feedback on LH, resulting in ovulation or an LH peak. The results suggest that progesterone may have a local inhibitory effect on the follicular oestradiol production.
\end{abstract}

\section{Introduction}

The role of progesterone in regulating human follicular function is not fully understood. Hoffman (1962) postulated that progesterone is responsible for suppressing follicular growth during the luteal phase in the normal menstrual cycle. Experiments by Goodman \& Hodgen (1977) on rhesus monkeys, and observations of Leyendecker, Wildt, Gips, Noche \& Plotz (1976) on women, indicate that progesterone might have an inhibitory effect on follicular function. The synthetic gestagen, medroxyprogesterone, administered via intravaginal rings, has also been shown to inhibit follicular development as indicated by plasma oestradiol levels (Thiery, Vandekerckhove, Dhont, Vermeulen \& Decoster, 1976).

Bendz (1977) demonstrated that there is an anatomical basis for a countercurrent exchange between utero-ovarian veins and ovarian arteries in the human adnexa. Transfer of krypton-85 from the uterine vein to the ovarian artery of women has been shown (Bendz, Einer-Jensen, Lundgren \& Janson, 1979). Progesterone, but not bovine serum albumin, is transferred from the uterine vein to the ovarian artery of ewes (McCracken \& Einer-Jensen, 1976). A possible transfer of progesterone from the uterine vein to the ovarian artery may therefore exist in women.

The present study was undertaken in order to investigate whether progesterone, administered continuously via intravaginal rings to give a low plasma concentration, affects the follicular oestradiol production in regularly menstruating women.

* Present address: Department of Obstetrics and Gynaecology, University Hospital, S-901 85 Umeå, Sweden. 


\section{Materials and Methods}

\section{Subjects}

Progesterone was administered intravaginally to 8 regularly menstruating, healthy volunteers, aged 22-39 years, with cycles of 27-30 days. All subjects had previously participated in studies with regular venous punctures. The intravaginal ring was inserted in the morning on Day 5 of the cycle (Day $1=$ the day when the last menstrual period started). Blood samples were taken on Days 4, 5 (before and $5 \mathrm{~h}$ after the intravaginal ring insertion), 6, 7, 9, 11 , 13, 16, 19 and 22 of the cycle. All samples were taken in the morning between 08:00 and $11: 00 \mathrm{~h}$. The rings were removed on Day 22.

The control group for serum FSH, LH and prolactin concentrations consisted of 9 healthy, regularly menstruating women, aged 19-43 years, giving daily blood samples throughout an ovulatory cycle.

\section{Progesterone intravaginal rings}

Each ring contained $708 \pm 4.7$ (s.d.) $\mathrm{mg}$ progesterone in the core of a silicone polymer ring (polysiloxane, Silastic 382: Dow Corning Company, Midland, Michigan, U.S.A.). The outer diameter of the ring was $60 \mathrm{~mm}$ and the thickness $9 \mathrm{~mm}$. The calculated release rate of progesterone is $10 \mathrm{mg} / \mathrm{day}$.

\section{Hormone analysis}

Plasma levels of oestradiol and progesterone were measured by radioimmunoassay after extraction with diethyl ether and $n$-hexane, respectively. Duplicate samples were used, and correction for recovery and for water blanks was undertaken in both methods. The blank was usually zero in both assays. Details of the preparation of samples and reagents were as described by Carstensen \& Bäckström (1976). In the present study, however, the paper chromatographic step used in the original procedure was omitted. The figures given below refer to these later variants.

For the determination of oestradiol-17 $\beta$, an antiserum to oestradiol-17ß-6 (Ocarboxymethyl) oxime-bovine serum albumin was used (prepared by $\operatorname{Dr} H$. R. Lindner, Weizman Institute, Rehovot, Israel). No significant difference was found between 10 different plasma samples analysed with and without paper chromatography $(414 \pm 396$ and $407 \pm 396$ pmol oestradiol/1 respectively). The coefficient of variation between these methods was $13 \cdot 3 \%$ and the coefficient of correlation $r=0.99$. The within-assay variation for the nonchromatographic method was $10 \%$ at oestradiol values below $370 \mathrm{pmol} / 1(n=100)$ and $7 \%$ at oestradiol values above that level $(n=132)$. The sensitivity of the assay was $35 \mathrm{pmol} / 1$ calculated according to Feldman \& Rodbard (1971). The regression line between known amounts of oestradiol $(x)$ added to plasma samples and the amounts recovered in the analysis (y) was $y=0.902 x+6.21 \mathrm{pg}, r=0.997$.

For the determination of progesterone, the antiserum used was to progesterone-11 (O-carboxymethyl) oxime-bovine serum albumin (Endocrine Science Inc., Tarzana, California, U.S.A.). The within-assay variation was $12.7 \%$ at progesterone values below $6.5 \mathrm{nmol} / 1$ $(n=100)$ and $6 \cdot 6 \%$ above that level $(n=100)$. Sensitivity of the assay was $80-200 \mathrm{pmol} / 1$ depending on plasma volume extracted (Feldman \& Rodbard, 1971). The regression line between known amounts of progesterone $(x)$ added to plasma samples and the amounts recovered in the analysis $(y)$ was $y=0.999 x-2.82 \mathrm{pg}, r=0.998$.

Serum levels of FSH and LH were determined radioimmunologically by a double-antibody solid-phase assay (Organon N.V., Oss, Holland). Antisera against FSH and LH and purified hormones for ${ }^{125} \mathrm{I}$-labelling were obtained from KABI AB, Stockholm, Sweden. The standards 
were Human Pituitary FSH 68/39 and Human Pituitary LH or ICSH 68/40 respectively (KABI $\mathrm{AB}$, Stockholm, Sweden). Serum prolactin was determined by radioimmunoassay using a kit from CEA-IRE-Sorin, Fleureus, Belgium. The values are expressed in terms of the human prolactin standard, NIH V L-S-2. Within- and between-assay variations were 8.0 and $10.5 \%$ for FSH, 8.7 and $8.7 \%$ for $\mathrm{LH}$ and 5.0 and $7.2 \%$ for prolactin. The sensitivities were 0.88 units FSH/l, 1.00 units $\mathrm{LH} / \mathrm{l}$ and $1.53 \mu \mathrm{g}$ prolactin/l respectively, the lowest dose being significantly different from zero (Feldman \& Rodbard, 1971).

\section{Statistical methods}

Differences between groups were tested by the Mann-Whitney U-test and differences within groups by Wilcoxon's paired rank sign test (Siegel, 1956). The follicular-phase FSH levels of the treated subjects and the controls were tested by one-factor analysis of variance (Wonnacott \& Wonnacott, 1972). The values in the text and in the figures are given as mean \pm s.d. calculated after a $\log$ transformation.

\section{Results}

In the present study an increase in plasma progesterone values above $35 \mathrm{nmol} / \mathrm{l}$ was used as an indication of the presence of a corpus luteum and ovulation since the maximal progesterone level noted during the first 2 days after insertion of the intravaginal ring was $20 \mathrm{nmol} / \mathrm{l}$. The mean of the values for Days 5 (p.m.) and Day 6 was $13.4 \pm 3.1 \mathrm{nmol} / 1$ which was significantly $(P<$ 0.001 ) higher than the mean of the values from Days 4 and 5 (a.m.), $1.80 \pm 1.11 \mathrm{nmol} / \mathrm{l}$. An increase in the plasma concentration of oestradiol was used as an indication of follicular growth. In each woman follicular growth was considered to have occurred if the plasma oestradiol level increased $100 \%$ above the mean concentration of the Day 4 and Day 5 (a.m.) samples. The mean of the oestradiol values from Day 4 and Day 5 (a.m.) of the total group was $218 \pm 74.5$ $\mathrm{pmol} / \mathrm{l}$.

\section{Plasma oestradiol concentrations}

There was an increase in plasma oestradiol values in 4 women. Three of these subjects had a later rise in plasma progesterone, indicating the presence of a corpus luteum and the highest measured plasma oestradiol levels were on Days 13,16 and 19. In the fourth woman plasma oestradiol reached a maximum on Day 22 , when there was also an LH peak. The plasma oestradiol values started to increase when the plasma progesterone levels were just below 10 $\mathrm{nmol} / \mathrm{l}$ in 3 of the women and about $7 \mathrm{nmol} / 1$ in the fourth woman. The plasma progesterone levels during the days of positive feedback of oestradiol on $\mathrm{LH}$ were between 7 and $10 \mathrm{nmol} / \mathrm{l}$. The mean plasma oestradiol levels in the 4 subjects who showed no oestradiol rise or late rise in plasma progesterone were between 154 and $230 \mathrm{pmol} / 1$ during the period of investigation.

\section{Plasma progesterone concentrations}

The mean plasma level of progesterone in the 4 women who did not show a rise in plasma oestradiol was $16 \mathrm{nmol} / \mathrm{l}$ by $5 \mathrm{~h}$ after insertion of the intravaginal ring. On Day 13 the mean concentration had decreased to $8.9 \mathrm{nmol} / 1$ (Text-fig. 1). In the 4 women showing an oestradiol rise the mean plasma progesterone level on the day of insertion was $9.2 \mathrm{nmol} / \mathrm{l}$ and increased up to $11 \mathrm{nmol} / 1$ the day after insertion. The mean level on Day 13 of the cycle was $8.4 \mathrm{nmol} / \mathrm{l}$. Three of these subjects had a late rise in plasma progesterone up to 36,37 and $62 \mathrm{nmol} / \mathrm{l}$, indicating the presence of a corpus luteum. The mean plasma progesterone concentrations of Days 5-13 were significantly lower in the ovulatory subjects compared to the anovulatory subjects $(9.8$ and $11.8 \mathrm{nmol} / 1$; ANOVA, $\mathrm{F}=6.40, P<0.05)$. 


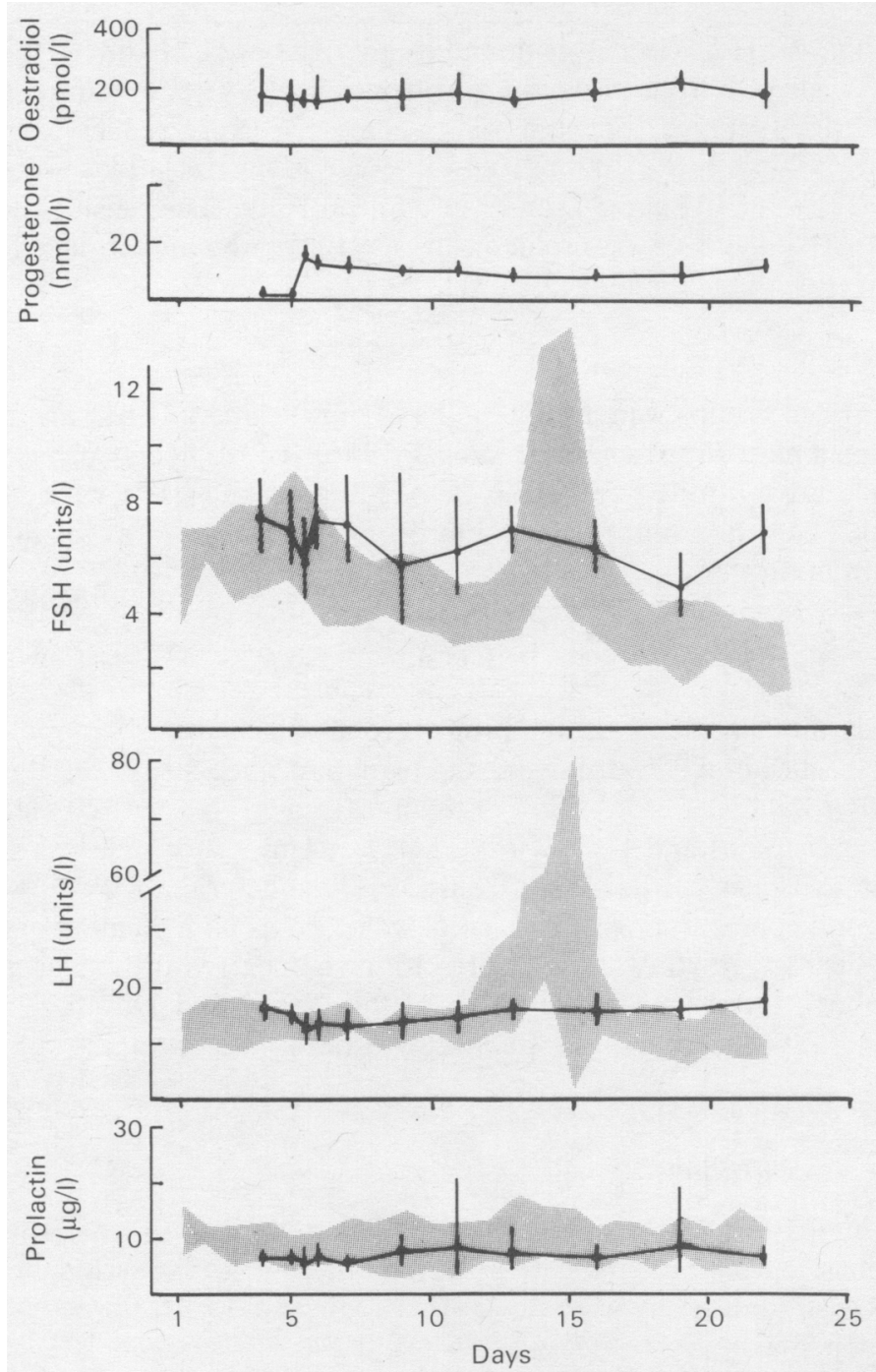

Text-fig. 1. Mean \pm s.d. peripheral levels (after log transformations) of FSH, LH, prolactin, oestradiol and progesterone in 4 women with a progesterone-releasing intravaginal ring (inserted on Day 5) and showing no signs of ovulation. The shaded area shows mean \pm s.d. of the control group $(\mathrm{N}=9)$.

\section{Plasma FSH, LH and prolactin}

The FSH levels of the treated women were significantly higher than those of the controls between Days 6 and 13 (one-factor analysis of variance: $F=16.4, P<0.0005$ for the anovulatory subjects and $F=24.6, P<0.0005$ for the whole group, 8 women). The time between Days 6 and 13 was chosen because Day 6 was the day after ring insertion, and Day 13 was before the gonadotrophin surge that occurred in the controls (Text-fig. 1).

The mean LH levels were all within the range of the controls except for Days 19 and 22 of the anovulatory subjects (Text-fig. 1). These mean levels were significantly increased compared to those of the controls $(P<0.006$ and 0.014 , respectively). No LH peaks were recorded in the ovulatory subjects, probably because of the intervals between the blood samples. One subject 
showed an LH peak value of 78 units/1 on Day 22 and also showed a preceding peak in plasma oestradiol. However, no significant increase in plasma progesterone was observed for this subject.

The mean plasma prolactin levels of the anovulatory subjects or the whole experimental group were not significantly different from the mean control values.

\section{Discussion}

The results from the present study indicate that plasma progesterone concentrations equivalent to low values in the luteal phase, achieved by intravaginal ring administration, may inhibit follicular-phase production of oestradiol. This effect was seen in 4 of the 8 women. In the other 4 subjects, who showed a plasma oestradiol increase, positive feedback of oestradiol on LH secretion seems to have occurred; all showed an LH surge or an increase in plasma progesterone concentration indicating the presence of a corpus luteum. The late rise of plasma progesterone would be an indirect sign of an ovulation which in vivo is preceded by a positive feedback.

FSH was significantly increased compared to that of the controls on certain days shortly after the insertion of the intravaginal rings. There was no significant decrease in FSH during the first week of treatment, suggesting that the effect of progesterone could be directly on the follicle. One can assume that the plasma FSH concentration in the early follicular phase is sufficient to stimulate follicular growth. If follicular growth, indicated by increasing plasma oestradiol levels, does not occur, even though the plasma FSH concentration is kept at the early follicular phase level, one would expect the failure to be located in the ovary. A similar interpretation has also been proposed for findings in rats (Fukuda, Katayama \& Tojo, 1980), rhesus monkeys (Goodman \& Hodgen, 1977) and women after vaginally administered medroxyprogesterone (Thiery et al., 1976). A progesterone cytoplasmic receptor has also been shown to be present in the human ovary (Jacobs, Suchocki \& Smith, 1980). The reason why not all of the subjects were anovulatory might be that the release of progesterone from the intravaginal ring was quite small. The plasma levels achieved correspond, in the early part of the experiment, with early luteal-phase levels. However, the progesterone concentration in the later part of the experiment was even lower and corresponds to preovulatory levels.

Our hypothesis is that progesterone inhibited oestradiol production locally in the ovary, but the concentration of progesterone achieved in the ovary was probably at the border line of its action and because of individual sensitivity and perhaps lower vaginal resorption of progesterone in the subjects with ovulation, oestradiol production was not inhibited in all subjects. This is supported by the findings of a higher ovulation rate in two similar studies using progesteronereleasing intravaginal rings, but with an even lower plasma progesterone level (Victor, Jackanicz \& Johansson, 1978; Toivonen, 1981). Thiery et al. (1976), however, did not find a single ovulation when using medroxyprogesterone-releasing intravaginal rings giving a steady plasma concentration of $5.8-11.6 \mathrm{nmol} / 1$.

This work was supported by the Swedish Medical Research Council project $4 x-5203$. We thank Professor K. Ahrén for supplying the oestradiol antiserum; Mrs G. Hällström and Mrs B. Wikström for technical assistance; Mrs L. Damber for statistical advice; and Mrs J. Robbins for correcting the English.

\section{References}

Bendz, A. (1977) The anatomical basis for a possible counter current exchange mechanism in the human adnex. Prostaglandins 13, 355-362.

Bendz, A., Einer-Jensen, N., Lundgren, O. \& Janson,
P.O. (1979) Exchange of krypton-85 between the blood vessels of the human uterine adnexa. $J$. Reprod. Fert. 57, 137-142.

Carstensen, H. \& Bäckström, T. (1976) A paper 
chromatographic saturation analysis method for measuring oestradiol, testosterone and $5 \alpha$ dihydrotestosterone from the same sample. J. Steroid Biochem. 7, 145-149.

Feldman, H. \& Rodbard, D. (1971) Mathematical theory of radioimmunoassay. In Principles of Competitive Protein Binding Assays, pp. 158-203. Eds N. D. Odell \& W. H. Daughaday. J. Lippincott Co., Philadelphia.

Fukuda, M., Katayama, K. \& Tojo, S. (1980) Inhibitory effect of progesterone on follicular growth and induced superovulation in the rat. Arch. Gynaek. 230, 77-87.

Goodman, A.L. \& Hodgen, G.D. (1977) Systemic versus intraovarian progesterone replacement after luteectomy in rhesus monkeys: differential patterns of gonadotrophins and follicular growth. J. clin. Endocr. Metab. 45, 837-840.

Hoffman, F. (1962) Über die Wirkung des Progesterons auf das Follikel-wachstum im Zyklus und seine Bedeutung für die hormonale Steuerung des Ovarialzyklus der Frau. Geburtsh. Frauenheilk. 22, 433440.

Jacobs, B.R., Suchocki, S. \& Smith, R.G. (1980) Evidence for a human ovarian progesterone receptor. Am.J. Obstet. Gynec. 138, 332-336.
Leyendecker, G., Wildt, L., Gips, H., Noche, W. \& Plotz, E.J. (1976) Experimental studies on the positive feedback effect of progesterone, 17 $\alpha$ hydroxyprogesterone and 20adihydroprogesterone on the pituitary release of $\mathbf{L H}$ and FSH in the human female. Arch Gynäk. 221, 29-45.

McCracken, J.A. \& Einer-Jensen, N. (1976) The counter current transfer of progesterone in the ovarian vascular pedicle. Proc. 5th Int. Congr. Endocrinology, Hamburg, Abstr. 775.

Siegel, S. (1956) Nonparametric Statistics. McGrawHill, New York.

Thiery, M., Vandekerckhove, D., Dhont, M., Vermeulen, A. \& Decoster, J.M. (1976) The medroxyprogesterone acetate intravaginal silastic ring as a contraceptive device. Contraception 13, 605-617.

Toivonen, J. (1981) Pituitary and gonadal function during the use of progesterone or progesteroneestradiol releasing vaginal rings. Int. J. Fertil. (In press).

Victor, A., Jackanicz, T.M. \& Johansson, E.D.B. (1978) Vaginal progesterone for contraception. Fert. Steril. 30, 631-635.

Wonnacott, T.H. \& Wonnacott, R.J. (1972) Introductory Statistics. Wiley, New York.

Received 26 January 1981 